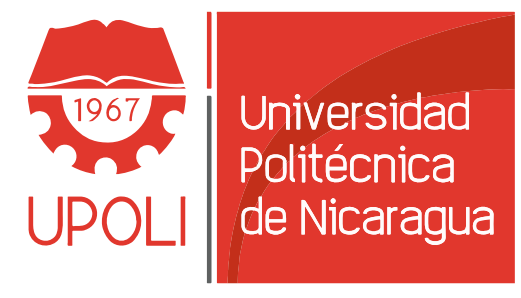

Sirviendo a la Comunidad

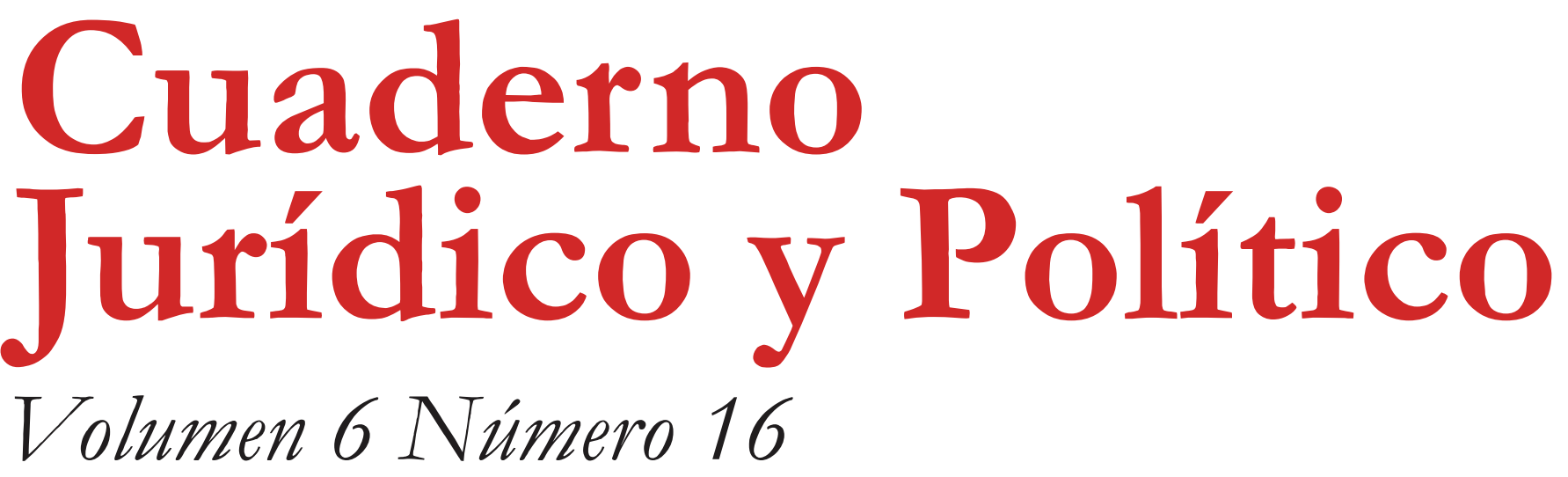

Publicación semestral • Managua, Nicaragua • Julio-Diciembre 2020

ISSN 2413-810X (versión impresa). ISSN 2414-4428 (en línea).

Informativo

Presentación

Jerson Cerda Tijerino

Avances y resultados de investigación

Cristian Rivas-Castillo | Karla Rodriguez Burgos | Carlos Miranda-Medina Oswaldo Leyva Cordero

Artículos

Jacqueline Esther Samper Ibáñez

Emilio José Almache Soto | Alcides Antúnez Sánchez

Julián Enrique Barrero García

Guillermo Ferriol Molina

Emma Patricia Muñoz Zepeda

Corpus iuris de derechos humanos

Gabriel Illescas Álvarez 
Cuaderno Jurídico y Político, Vol. 6, Nro. 16, julio-diciembre de 2020.

Universidad Politécnica de Nicaragua. ISSN 2413-810X | Págs. 121-126.

\section{LA CIDH Y SU REDESCA INSTAN A ASEGURAR LAS PERSPECTIVAS DE PROTECCIÓN INTEGRAL DE LOS DERECHOS HUMANOS Y DE LA SALUD PÚBLICA FRENTE A LA PANDEMIA DEL COVID-19 \\ THE IACHR AND ITS REDESCA CALL FOR ENSURING THE PROSPECTS \\ FOR INTEGRAL PROTECTION OF HUMAN RIGHTS AND PUBLIC HEALTH}

FACE TO THE COVID-19 PANDEMIC

\section{Sumario \\ Medidas especiales y limitaciones a la regresividad | Empresas y Derechos Humanos | Deber de atención especial sobre grupos en situación de vulnerabilidad \\ Comisión Interamericana de Derechos Humanos ${ }^{1}$}

Washington, D.C. - La Comisión Interamericana de Derechos Humanos (CIDH) y su Relatoría Especial sobre Derechos Económicos, Sociales, Culturales y Ambientales (REDESCA) reconocen la complejidad que enfrentan los Estados y las sociedades del hemisferio debido a las medidas excepcionales que requiere la pandemia global ocasionada por el coronavirus COVID19 que avanza en forma exponencial y que, al 15 de marzo, ya se había cobrado 6.610 vidas a nivel global y 46 en el hemisferio. Esto supone desafíos extraordinarios desde el punto de vista de los sistemas sanitarios, la vida cotidiana de las personas y para la vigencia de los derechos humanos en el marco de sistemas democráticos.

Dentro de este contexto, la Comisión observa que los Estados de la región están realizando importantes esfuerzos en la adopción de medidas dirigidas tanto a la atención y tratamiento de las personas afectadas por el COVID-19, como a la contención de la pandemia declarada por la Organización Mundial de la Salud. Estas últimas incluyen cuarentena, distanciamiento o aislamiento social, limitaciones de circulación a nivel nacional e internacional, como orientaciones preventivas de higiene personal y comunitaria. La CIDH y su REDESCA refuerzan el llamado de las organizaciones internacionales especializadas para que la adopción y la implementación de dichas medidas se ajusten a los estándares de protección de los derechos humanos. Dichos estándares se verifican a través del respeto a las garantías y libertades fundamentales, la plena información a las poblaciones sobre las medidas y políticas implementadas en sus territorios, como a través de los recursos disponibles para estos efectos. Asimismo, mediante la aplicación

\footnotetext{
${ }^{1}$ Nota del editor. El contenido de este apartado es una adaptación del texto oficial publicado por la Comisión Interamericana de Derechos Humanos conforme a las directrices editoriales de la Revista Cuaderno Jurídico y Político preparado por el equipo de la Revista Cuaderno Jurídico y Político.
} 
de una perspectiva interseccional, sensible en términos culturales, basada en los principios de igualdad y de diversidad de género.

Respecto a las medidas de atención, la CIDH y su REDESCA recuerdan a los Estados que el derecho a la salud se debe garantizar a todas las personas dentro de su jurisdicción, sin ningún tipo de discriminación, de conformidad con los estándares e instrumentos interamericanos e internacionales de derechos humanos. Así, enfatizan que para hacer efectivo el derecho a la salud los siguientes elementos son esenciales e interrelacionados: la disponibilidad, la accesibilidad, la aceptabilidad y la calidad. En virtud de este derecho los Estados deben brindar una atención y tratamiento de salud oportuna y apropiada; destacándose que todos los establecimientos, bienes y servicios de salud deben ser accesibles sin discriminación alguna, y adaptarse en función de circunstancias como las que la presente pandemia plantea con apego al principio «pro persona», a fin de que prevalezca el debido y oportuno cuidado a la población por sobre cualquier otra pauta o interés de naturaleza pública o privada. Dada la naturaleza la pandemia y las medidas de contención, también debe brindarse una particular atención a la salud mental de la población.

Adicionalmente, la CIDH y su REDESCA recuerdan que los Estados deben tomar como prioridad la integridad y bienestar de las personas profesionales de la salud frente a la pandemia, considerando asimismo fundamental que los Estados tomen medidas específicas para la protección y reconocimiento de las personas que asumen socialmente tareas de cuidado, formal o informalmente, con reconocimiento de las condiciones sociales preexistentes y de su agudización en momentos de especial exigencia para los sistemas de salud y asistencia social. En relación con las trabajadoras y los trabajadores del sector salud, se destaca la importancia de la adopción de protocolos a ser aplicados en el tratamiento del COVID19, así como de medidas especiales para la protección y entrenamiento de las personas sanitarias, lo que incluye que dispongan de equipos de protección personal y para la desinfección de ambientes, así como la debida garantía de sus derechos laborales y de seguridad social.

En relación con las medidas de contención, la CIDH y su REDESCA urgen a los Estados que observen, en cualquier acción dirigida a la reducción de los factores de contagio, el estricto respeto a los tratados y estándares internacionales en materia de derechos humanos, las garantías del Estado de Derecho y el cumplimiento de la obligación de cooperación de buena fe, particularmente en contextos transnacionales de alto riesgo para la salud pública y la vida de las personas.

En tal sentido, la CIDH y su Relatoría Especial para la Libertad de Expresión (RELE) reconocen que, frente a estados de emergencia, los Estados pueden adoptar restricciones temporales a los derechos humanos. A la luz de este contexto, estas medidas deben sujetarse a la estricta observancia de la finalidad de salud pública, estar acotadas temporalmente, tener objetivos definidos, además de ser estrictamente necesarias y proporcionales al fin perseguido. Adicionalmente, los Estados no pueden suprimir o prohibir los derechos y las libertades de manera genérica y, en especial, no deben limitar la libertad de los medios de comunicación, las organizaciones y liderazgos sociales o políticos, para buscar y difundir información por cualquier medio.

En todo caso, la Comisión exhorta a los Estados y a las instituciones de derechos humanos a garantizar el acceso a los mecanismos de denuncia y protección frente a posibles limitaciones indebidas o violaciones de derechos derivadas de tales medidas que garanticen transparencia, 
acceso a la información, protección de datos personales, consentimiento informado, acceso a la justicia y debida reparación.

Asimismo, los Estados deben observar la obligación positiva de informar en forma completa, permanente y veraz sobre la evolución epidemiológica de la pandemia y las medidas que adoptan para combatirla y emitir directivas precisas dirigidas a prestadores de salud para preservar la privacidad de las personas afectadas en cuanto a su estado de salud. En especial, las personas con liderazgo político en los diferentes niveles de gobierno tienen una alta responsabilidad en coordinar con los órganos rectores en materia de salud, asegurando que sus mensajes sean coherentes con los hallazgos científicos y las medidas adoptadas.

\section{Medidas especiales y limitaciones a la regresividad}

Por otra parte, la Comisión y su REDESCA resaltan que deben tutelarse los derechos de todas las personas que se vean afectadas por las medidas de contención que se impongan, especialmente aquellas cuya subsistencia peligre al someterse a un régimen de cuarentena, por la pérdida de sus ingresos, amenazas a sus necesidades vitales básicas, riesgo de ser desalojadas o ausencia de redes institucionales de apoyo. La CIDH y su REDESCA, conscientes de los altos desafíos que este contexto de pandemia supone para los Estados y la población en general, subrayan la necesidad de que cualquier medida de naturaleza restrictiva o regresiva con respecto a los DESCA, sea adoptada y aplicada de forma transparente, tras un cuidadoso análisis de las alternativas existentes. De adoptarse, dichas medidas deben estar justificadas desde un enfoque de derechos humanos con el debido análisis de impacto en los mismos, así como de la más eficiente utilización de los máximos recursos disponibles.

En ese sentido, la REDESCA observa que los Estados deben valorar de manera urgente, tanto nacional como regionalmente, dar respuestas eficaces para mitigar los impactos de la pandemia sobre los derechos humanos, mediante la adopción de una combinación adecuada de marcos normativos y políticas públicas a corto y mediano plazo relacionados, por ejemplo, con el alivio de crédito, esquemas de reprogramación y flexibilidad de pagos de deuda o y cualquier otro tipo de obligación monetaria que pueda imponer una presión financiera o tributaria que ponga en riesgo los derechos humanos, así como con la implementación de medidas compensatorias proporcionales en casos de pobreza y pobreza extrema o de fuentes de trabajo en especial riesgo.

Asimismo, la CIDH y su REDESCA alientan a los Estados y otras partes interesadas a coordinar esfuerzos para generar iniciativas de cooperación regional general que incluyan el fortalecimiento de los sistemas públicos de salud, la promoción de esquemas solidarios de apoyo económico, la cooperación científica, la vigilancia epidemiológica, la producción de información o datos médicos adecuados y oportunos, así como planes colaborativos de mitigación de impactos sobre el derecho al trabajo, con el fin de contener los impactos de la pandemia en las poblaciones más excluidas, así como en aquellos Estados con menores capacidades sanitarias de respuesta o sistemas de salud más frágiles. A tal fin, la REDESCA se pone a disposición de la OEA y sus Estados miembros para estimular y facilitar diálogos nacionales o regionales que coadyuven con tales propósitos. 


\section{Empresas y Derechos Humanos}

Los Estados también deben exigir que las empresas, como empleadoras en general, respeten los derechos humanos y tengan un comportamiento ético y responsable, particularmente por los impactos en trabajadoras y trabajadores, consumidoras y consumidores y comunidades locales. La CIDH y su REDESCA recuerdan que las empresas son actores claves para la realización de los derechos humanos, de allí que, en el actual contexto de pandemia, las políticas y ajustes que implementen deben priorizar su responsabilidad de respetar los derechos humanos, particularmente los derechos laborales por los previsibles efectos en los mismos. La organización de trabajo remoto o teletrabajo, cuando resulte factible; o el entendimiento de que esta es una situación de aislamiento y limitaciones por condiciones sanitarias de emergencia, y no así de vacaciones obligatorias, por ejemplo, pueden facilitar en algunos casos, la continuidad de labores, reduciendo impactos negativos en el ámbito de los derechos laborales.

En esa línea, las autoridades estatales competentes deben cooperar y guiar a las empresas para la implementación de medidas de mitigación sobre los efectos de esta crisis sanitaria desde el enfoque de los derechos humanos. En particular, se debe asegurar que las instituciones privadas de salud y de educación no estén exentas de cumplir con sus responsabilidades de respetar los derechos humanos, sino que están llamadas a cooperar con las autoridades y aunar esfuerzos para mitigar los impactos que se puedan generar sobre los derechos a la salud y a la educación.

Por otro lado, la CIDH y su RELE también exhortan a las empresas de comunicación a contribuir con la población proporcionando información rigurosa, chequeada y observar en todo momento los códigos de ética y de actuación. Asimismo, felicitan a los medios de comunicación de la región que han establecido un acceso gratuito y abierto a los contenidos vinculados con la pandemia.

\section{Deber de atención especial sobre grupos en situación de vulnerabilidad}

La Comisión y su REDESCA observan que, por su carácter pandémico, la respuesta al COVID-19 adquiere una dimensión global y local para el resguardo de los derechos humanos de las personas afectadas. Globalmente, es necesaria la estrecha cooperación y coordinación de todos los Estados e instancias internacionales competentes, incluyendo la evaluación de solicitudes y entrega de fondos financieros de emergencia como de información científica, con el fin de disminuir los contagios y muertes por esta causa. Asimismo, la CIDH nota que a nivel internacional las poblaciones en procesos de desplazamiento o migración se ven especialmente afectadas al carecer de sistemas de protección de salud y de apoyo social, siendo susceptibles de sufrir estereotipos, restricciones de movimiento y retóricas de culpabilización u odio. La CIDH insta a los Estados para que las medidas de contención del patógeno no impliquen el incumplimiento de sus obligaciones internacionales de protección frente a las poblaciones que huyen de la persecución, el conflicto o de riesgos para su vida e integridad.

Localmente, procesos pandémicos producen impactos desproporcionados sobre poblaciones con mayores dificultades de acceso a estructuras sanitarias y tecnologías de atención a la salud dentro de los países, como pueblos indígenas, campesinado, personas migrantes, personas privadas de la libertad, grupos sociales en las periferias de las ciudades y los grupos económicos desatendidos por las redes de seguridad social, como son las y los trabajadores del sector informal o personas en situación de pobreza o de calle. A su vez, dado el carácter viral de la transmisión del COVID- 
19 ciertos grupos sociales se encuentran en mayor riesgo de sufrir impactos diferenciados y que sus derechos sean afectados más fácilmente, como son las personas con discapacidad, personas con determinadas patologías y enfermedades, y particularmentelas personas mayores. En relación con estos grupos las medidas que se adopten deben incluir acciones de prevención del contagio y de garantía de la atención y tratamiento médico, medicamentos y provisiones evitando los impactos diferenciados del desabastecimiento; así como de acceso a la información en formatos adecuados a los diferentes grupos y sus necesidades diferenciadas.

Con respecto a las personas privadas de libertad, la Comisión exhorta a los Estados a considerar en los protocolos de atención los derechos de esta población a efectos de evitar brotes en los diferentes centros de detención, y que en el caso de que ocurran, se tenga acceso a los tratamientos de salud adecuados. Los Estados también deben adoptar medidas alternativas a la privación total de la libertad, siempre que fuera posible, evitando el hacinamiento en las cárceles, lo que puede contribuir con la propagación del virus.

En cuanto a los pueblos indígenas, la CIDH recuerda a los Estados el deber de protección especial que debe ser dedicado a esa población y la importancia de proporcionarle información sobre la pandemia de forma sencilla y, en lo posible, en su idioma tradicional. Adicionalmente, la CIDH hace un llamado especial a los Estados para que respeten, de forma irrestricta, el no contacto con los pueblos y segmentos de pueblos indígenas en aislamiento voluntario, dados los gravísimos impactos que el contagio del virus podría representar para su subsistencia.

Acerca de las niñas, los niños y adolescentes (NNA), la CIDH y su REDESCA subrayan la importancia de que los Estados hagan primar su interés superior frente a la pandemia, por ejemplo, ajustando sus planes educativos y de dotación de alimentos para escolares a estas circunstancias de emergencia, generando medidas destinadas a que NNA no sufran un impacto desproporcionado en sus derechos a la educación y a la alimentación. Al respecto, destacan la importancia de que las medidas de aislamiento social incluyan, en la medida de las posibilidades, alternativas que les permitan mantener las actividades conducentes a su desarrollo, como clases a distancia.

Adicionalmente, los Estados deben tomar especialmente en cuenta su obligación de debida diligencia con los derechos de las mujeres, e implementar medidas para prevenir tanto casos de violencia de género, como intrafamiliar y sexual durante el aislamiento social, disponiendo de mecanismos seguros de denuncia y atención para las víctimas.

Finalmente, la CIDH y su REDESCA hacen un llamado a la calma a toda la región, indicando que esta es una pandemia que está siendo continuamente monitoreada por los Gobiernos y las autoridades nacionales en sus respectivas competencias, así como por los organismos internacionales, incluida la OEA, la Organización Panamericana de la Salud y la Comisión con sus Relatorías Especiales (DESCA y Libertad de Expresión). La naturaleza y los alcances de una emergencia de salud sin precedentes en la región y en el mundo, exigen dotar de contenido real a los principios de solidaridad y de responsabilidad compartida, con base en la cooperación internacional, que deben orientar tanto el accionar de los Estados, como de la sociedad en su conjunto. 
La REDESCA es una Oficina autónoma de la CIDH, especialmente creada para apoyar a la Comisión en el cumplimiento de su mandato de promoción y protección de los derechos económicos, sociales, culturales y ambientales en el continente americano.

La CIDH es un órgano principal y autónomo de la Organización de los Estados Americanos (OEA), cuyo mandato surge de la Carta de la OEA y de la Convención Americana sobre Derechos Humanos. La Comisión Interamericana tiene el mandato de promover la observancia y la defensa de los derechos humanos en la región y actúa como órgano consultivo de la OEA en la materia. La CIDH está integrada por siete miembros independientes que son elegidos por la Asamblea General de la OEA a título personal, y no representan sus países de origen o residencia 


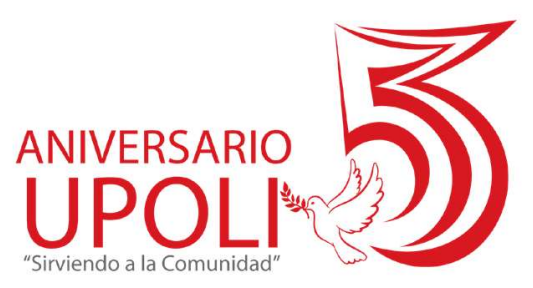

CUADERNO JURÍDICO Y POLÍTICO, CJP, es una revista académica semestral del Instituto Centroamericano de Estudios Jurídicos y Políticos, ICEJP-UPOLI. CJP es un espacio abierto y plural en el que convergen las voces de actoras y actores del Estado, la sociedad civil organizada y la academia nacional y regional, mediante la publicación de los trabajos que estos actores nos envían. 